Article

\title{
Sacred Places and Planetary Stresses: Sanctuaries as Laboratories of Religious and Ecological Change
}

\author{
Willis Jenkins \\ Religious Studies, University of Virginia, Charlottesville, VA 22902, USA; willis.jenkins@virginia.edu
}

Received: 10 March 2020; Accepted: 21 April 2020; Published: 27 April 2020

\begin{abstract}
How are global relations and planetary flows experienced, interpreted, and managed from places set aside from everyday use, as "sacred" in that sense? Sanctuary Lab, a transdisciplinary initiative at UVA, investigates how religious processes interact with planetary stresses. Provisionally adopting a keyword in religious studies, the sacred, opens a post-disciplinary angle of inquiry into Anthropocene processes of cultural and environmental change. Focusing on dynamics of change in places regarded as sanctuaries affords unique perspective on how rapid planetary changes interact with particular inherited streams of normativity and imagination. This essay integrates field note illustrations from Yellowstone and Bhutan with critical reflection on the lab's approach in order to share initial hypotheses, collaborative research practices, and potential significance. It suggests that sacralization is part of the process through which cultures make sense of rapid changes; that nonhumans participate in sacralization; that sanctuaries offer unique laboratories of coupled change; and that arts-based exercises can help drive critical reflection on experience and method.
\end{abstract}

Keywords: sacred; Yellowstone; Bhutan; Jordan River; climate change; religion; Anthropocene; multispecies

How are Anthropocene relations bearing on religion, and how are religious processes shaping Anthropocene futures? Some form of that question guides recent work from scholars interpreting religious dimensions of rapid ecological and cultural changes (Veldman et al. 2014; Deane-Drummond et al. 2017; Latour 2017; Sideris 2017; Jenkins et al. 2018; Haberman n.d.). Among the challenges for this growing area of research, scholars often note that its lead question needs methodological experiment, interdisciplinary collaboration, and contextual specificity. This essay aims to advance ideas for researching contextual interactions of planetary stress with inherited formations of religion by thinking with Sanctuary Lab, a transdisciplinary initiative at the University of Virginia studying how shifting global relations and planetary stresses are experienced, interpreted, and managed from places set aside as special-as sacred, in that sense.

"As the flows of energy and matter around the world are altered, and a new geological epoch emerges, what will become of the sacred?" So asks Szerszynski (2017a, p. 235), who suggests that the Anthropocene may be driving cultural shifts analogous in scope to those of the Axial Age. The wager of Sanctuary Lab is that by asking how shifting flows of energy and matter interact with particular sacred places, researchers may create lines of inquiry into what is becoming of the traditions and societies that interpret those places as sacred. It therefore investigates political and environmental consequences of sacralization processes, their vulnerability to rapid planetary shifts, and the implications of their interaction with those shifts.

Sanctuaries offer a unique vantage into ecological and cultural change insofar as they are places set aside from normal pressures and uses. They are valuable for inquiry into change precisely because they are often imagined to offer refuge from change. Pressures on them, we hypothesize, must exert pressure on the traditions and processes by which they have been made special. I co-direct the lab with Kurtis Schaeffer (Tibetan Buddhism) and Martien Halvorson-Taylor (Hebrew Scriptures), which 
also includes faculty in Environmental Sciences, Music, Chemistry, Astronomy, Anthropology, and Law. Local experts join the team for each site. We focused on Yellowstone in Winter 2018; Bhutan in Winter 2019; delayed a 2020 focus on the Jordan River Basin due to the COVID-19 pandemic; and have further sites in early planning stages. The pause in the lab's sequence due to the pandemic presents an opportunity to share these mid-course lines of reflection on the experiment.

Szerszynski's creativity in answering his lead question has been stimulating. In recent years he has composed narrative performance pieces that imagine futures of religious life reshaped by planetary forces (Szerszynski 2017b). For example, his "Martian Book of the Dead," describes the script for an AI program used on a terraformed Mars to prepare dying Buddhists to merge with the becoming of their adopted planet. It is meant to be performed on stage with another, written as if by an historian of religion toward the end of the 22nd century on Earth. Szerszynski's integration of religious and geological scales, as well as his performative mode, seems apt. Sanctuary Lab asks: can we make from our scholarly tools and knowledges real-time ways to investigate, archive, and dramatize the shifting interactions of rapid planetary change with particular inherited streams of normativity and imagination? What possible future landscapes of religion emerge as we do?

Because the lab employs multiple methods and organizes collaborative inquiry along the experience of an itinerary, this essay integrates narrative vignettes with conceptual reflection. Working from sketched illustrations of field notes, it develops speculative lines of inquiry into contextual interactions of planetary stress with inherited formations of religion. The unconventional style of academic writing reflects the experiment. In each section I convey how a certain angle of inquiry emerged from the lab's participants and processes and sharpen it in connection to related scholarship. I also develop tension between sections to stimulate critical reflection on the lab's terms and suggestions. My claims here are as provisional as sketched illustration and speculative inquiry suggest. I could not offer interpretation adequate to any of these sites nor to the histories of scholarship attending each. My purpose is to share hypotheses, comparative questions, and collaborative research practices that have emerged from the lab as its researchers work together to investigate how cultural processes are interacting global flows and planetary stresses in particular places.

\section{Thresholds of Yellowstone}

The ecologist's voice broke as he described climate-driven scenarios of ecosystem shifts. Mike Tercek has worked at Yellowstone for decades as a research scientist, beginning with a dissertation on Ross's Beautygrass, a plant endemic to Yellowstone. Tercek has since developed a specialty in climate projections, and in fact coded a program to aggregate climate-related information from various environmental monitors in the park, to aid park-specific modeling. The program is now used by a number of other national parks. We had asked Tercek to brief the team on climate science at Yellowstone. Seeing the scope of the lab's interests, he asked if he could also say something personal about how he understood the implications of those changes. Welcomed to do so, Tercek quoted Emerson, Thoreau, Muir, and the subsequent American wilderness tradition to explain what this landscape means to him. Long periods alone in backcountry forest are central to his understanding of himself and to his coping with existence. "I'm not religious," he said, "but I sense a presence here; in the deep wilderness. I feel known and healed; my ego is overcome there."

But now the healing power of backcountry forest seems imperiled. The highest correlation in North America between climate change and increased fire intensity lies within Greater Yellowstone Ecosystem. The park-specific data his program has aggregated, correlated with the IPCC warming scenario pathway representing current emissions, projects that within a few decades, 100 per cent of the park will burn every ten years (Tercek 2019). Yellowstone is likely to lose all of its forest. Tercek lives with the anxiety of loss, to the extent, he says, that it makes him feel physically sick, nauseous. He hikes into the backcountry forest now and, instead of being overcome and reoriented, he experiences a kind of moral vertigo. 
A conventional religious tradition is not required to sacralize a place (Howe 2016). The several streams of settler culture that came together to imagine Yellowstone National Park as a non-religious spiritual retreat included the transcendentalisms of Emerson and Thoreau and the Romantic sublime of Muir. The merging of those streams into the American wilderness tradition, opened what Jedediah Purdy has described as "secular pilgrimage, a seasonal passage into landscape whose sacral quality lay in its power to bring on the epiphanies Thoreau urged" (Purdy 2015, pp. 127-28). Yellowstone became a template for national nature parks as secular sanctuaries set aside for elevating purposes of human enjoyment. If not everyone entered with spiritual purposes, secular pilgrimage names the practice that recognized and legitimated the park's highest function: to draw one into a renewing encounter with nature. Yet that sacral quality, that power to elicit suspensions of self, now seems imperiled to Tercek and to others who share the tradition of wilderness parks as places of spiritual encounter. They seem to be experiencing a shift from Yellowstone as a refuge from social ills to instead a crucible of them. If so, that would represent another historic reversal in the settler American experience of wilderness. What will happen to the environmental norms and senses of self that it carries?

Part of the trouble with wilderness, of course, is that it conceals its sacral quality in naturalizing discourse, as if wilderness were a natural kind, the park boundary tracing an empirical geological feature. The suspensions of self in this secular pilgrimage have historically depended on regarding seized territory as uninhabited and primeval. I will return to that expulsive dynamic with sanctuaries. For now my point is just that supposedly secular sanctuaries are as eligible for critical attention as the conventionally marked sort in the Buddhist kingdom of Bhutan or the "Holy Lands" surrounding the Jordan River.

Any border creates cultural and political tensions; the borders of sacred places can be especially charged because they compel reflection on what is meaningful enough to suspend ordinary life. By suspending at its threshold the ordinary regime of values that shape life outside it, they stimulate reflection on the sources of goodness and meaning both within and without the boundaries. That is why, writes sociologist Justin Farrell, minor management issues at Yellowstone so quickly erupt into deep conflicts and continent-wide debates: "Because Yellowstone is such a symbolically important and even sacred place for so many Americans," he writes, "it serves as an emotional lightning rod that reveals in stark terms our nation's moral boundaries around nature" (Farrell 2015, p. 30). How its boundary is managed - for bison and wolves, tourists and snowmobiles—represents for many what is sacred, good, or meaningful.

What then happens to those ideas of the sacred and the conflicts between them as planetary warming moves ecological thresholds the boundary is meant to protect? When the bison seek to migrate out as invasive grasses move in, as snow retreats and fires grow? As visitor numbers rise with increased desire for contact with what the boundaries around Yellowstone represent? Responses to those questions will reshape American ideas of nature and certain practices of self-formation.

As Tercek's comportment disclosed, those responses may show up in affect as much as in word or text. Pressures on Yellowstone's threshold may alter long-lasting moods, circuits of feeling, or patterns of sensory embodiment. The sort of religion that makes Yellowstone's boundary into a culturally significant threshold is not just about formal beliefs about nature or the sacred, but especially "about the way things feel," as Donovan Schaefer argues; "the way our bodies are guided through thickly textured, magnetized worlds" (Schaefer 2015, p. 4). Schaefer calls for research on religion to seek "the way that bodies are shot through with the affects evoked by the world" (p. 106), as a mammalian evolutionary affordance shaped by material networks of culture and power. For Sanctuary Lab, that entailed studying the networks of thought and practice that have shaped ways of interacting with national parks generally and Yellowstone particularly. It also entailed crossing the boundary ourselves, observant of our own experiences and attentive to how those deeply shaped by the threshold seemed to experience it. 


\section{Sanctuary as Laboratory}

Sanctuary Lab takes a keyword in Religious Studies, the sacred, to open a line of inquiry into how cultural processes are interacting with rapid environmental changes. "Sacred" is of course a contested concept, deployed in service of various theories of religion. Skirting disciplinary arguments over whether or what is religion, Sanctuary Lab uses the term to convene post-disciplinary collaborative inquiry into places that seem invested with special significance by contingent alliances of imagination and power. We do not suppose that sanctuaries are necessary geographical designations any more than we suppose that they are natural geological features; they are imagined by human communities and made by political acts.

The Sacred Natural Sites initiative, a decades-running global effort supported by International Union for the Conservation of Nature (IUCN), describes places "'set aside' for purposes spiritual and religious" (Verschuuren et al. 2012, p. 1). What are those kinds of purposes? Sometimes they may be those of an historically recognized religion but, as the Yellowstone example shows, sometimes those purposes are perceived as non-religious by people whose sense of self and belonging are deeply shaped by them. I would prefer to say that these places are set aside for the sake of that which vests meaning in some shared sense of everyday life. Indeed, the act of setting aside helps generate a sense of the everyday by distinguishing places through which meanings of everyday life may be uniquely encountered.

"In these places nature and humanity meet," write editors from the IUCN project, "and people's deeper motives and aspirations are expressed through what is called 'the sacred'" (Verschuuren et al. 2012, p. 1). Their phrase, "what is called 'the sacred,'" acknowledges that they employ the term as a provisional bridge concept. It permits comparison of lands made special in many different ways for different purposes, which, for them, then provides a basis for coalition building by communities facing serial threats from global forces. Near the end of his book on countercultural sacred places, Adrian Ivakhiv writes: "sacred places are the physical and geographic anchor points for our psychic and cultural imaginings, the stories we tell about ourselves, the world and the relations between them" (Ivakhiv 2001, p. 239). These geographies are (in some way, for some people) densely knotted with significance.

Convening research in sites regarded as sacred affords unique perspective into how cultural imaginations are interacting with planetary changes. Precisely because a place is densely knotted with significance, standing as an anchor point in some understanding of the world, new global flows and planetary stresses seem likely to send reverberations through the imaginations and stories by which it was set apart. Sacred places thus seem to offer unique vantages into experiences of the Anthropocene. Belden Lane in the opening to his Landscapes of the Sacred writes: "To experience a place as sacred is to participate, knowing or unknowingly, in a whole history of cultural tensions and conflicting claims, even ecological shifts in the terrain itself" (Lane 2001, pp. 3-4). Sanctuary Lab asks how rapid ecological shifts and new global flows affect the experience of these places and the management of their conflicting claims, with what implications for the moral imaginations by which they are made special.

We question, in other words, how the sacralizing processes that led to these places being set apart now interact with Anthropocene relations. Approaching landscapes with that grand mace, "the Anthropocene," our aim is not reductive analysis, to fold the many stories by which people and places are differentiated into an epochal narrative. On the contrary, we seek the particular histories, traditions, and practices through which people are interpreting and negotiating planetary stresses. In academic discourse, the term often names the challenge of imagining unprecedented and conflicting scales of human and nonhuman agencies unfolding in multiple temporalities (Latour 2014; Chakrabarty 2018). One of the liabilities of Anthropocene discourse is that its planetary scope and species-level vocabulary, especially when embedded in a managerial framework, abstracts from the languages, values, and practices through which people experience particular environments. An important role for environmental humanities lies in pluralizing the relations invoked by the term 
Anthropocene and describing how different conceptions of value and purpose interact with them (Castree 2014).

Nor do we, by working with a term from Religious Studies, wish to reduce multiple ways of knowing and being into a notion of religion bounded off from the secular. On the contrary we use "sacred" to mark places of biocultural difference that must be understood by the diverse forms of imagination and power that have made them special. Because these places are made special through particular cultural inheritances and specific cosmological practices, our wager is that we can investigate where and how Anthropocene forces and powers enter particular worlds, and the diversity of experimental futures being made with them.

Used obtusely, those perilous inventions of analysis, "religion" and "Anthropocene," can distort more than they illuminate about what is happening in particular places, relations, and communities. The term "sanctuary" draws on a spatial concept with a long history of marking places as sacred in order to interpret broader powers and to create refuges from their dangers. Observing historical and contemporary movements within which designated sanctuaries create immunity from secular, sovereign authorities, James Chappel in fact proposes sanctuary as a key concept for post-secular study of global religion. By establishing a geographical site from which to resist some simplifying matrix of power, "what the concept of sanctuary does, essentially, is announce that this place shall not be governed by the sovereign" (Chappel 2020, pp. 24-25). These places recombine religion and secularity, political subjectivity and the state, in ways that, by offering refuge from dangers, produce alternative formations of human experience. What happens, then, when the sovereign is entangled with anthropogenic planetary change? How to create possibilities of immunity from climate forcing or accelerated sea-level rise?

Sanctuaries present especially valuable sites for those kinds of inquiry because they are often imagined to offer refuge from change, as places set aside from normal powers or pressures. The traditions by which they are sacralized must then reckon with changes, incorporating them into the meaning of the place, and so may face acute pressure in the face of unprecedented rates of change or exogenous drivers. What happens in these special places, dense with interpretive significance for particular communities, will then shape how those communities imagine and make futures.

Those interpretations need not explicitly acknowledge planetary pressures in the way that Tercek did with climate crisis at Yellowstone. In many contexts, Anthropocene stress on religious interpretation may be more oblique, indirect, and unthematized (Jenkins 2017). Just so, it will still shape how communities make their way with these forces, temporalities, relations, and anxieties.

We thus treat sanctuaries as laboratories of coupled cultural-environmental change. In Moral Laboratories, the anthropologist Cheryl Mattingly uses the term to focus on how families face challenges and shifting conditions by experimenting with what they have inherited. She observes how "small events can serve as experiments in possible futures" (Mattingly 2014, p. 73). Analogously, we listen for how places experiment with their inheritances and especially listen for those moments in which we hear participants in those places experimenting with possible futures. The research theme then is not one of simple threat: sacred places imperiled by Anthropocene forces. Rather, we suppose that sacralization is often part of the process through which cultures make meaning of rapid changes, and thus part of various experiments in possible futures.

\section{Bhutan as Beyul}

Consider Bhutan's self-presentation as a Buddhist sanctuary. Into this land's received tradition as refuge for teachers and treasures of Vajrayana Buddhism the nation now incorporates ecological conservation and also, with Gross National Happiness, an enlightened refuge from excessive capitalism. In high-profile international settings its leaders have announced that the country is carbon negative and, supported by a constitutional mandate to maintain sixty percent forest cover, have pledged to remain carbon negative in perpetuity. Those policies, combined with restrictions on development and tourism, make it a place set apart. 
Attractive to patrons and pilgrims, the policies may also help Bhutan negotiate threats of geopolitical pressure and planetary change. As it elevates its sanctuary status, the international regard may help protect it from the fate of Tibet to its North and Sikkim to its West. Temples along key river valleys undertake an elaborate annual ritual to maintain spiritual protection from any calamities that might come through the mountain passes, including military invasion. Those same river valleys are vulnerable to devastating glacial lake outburst floods (GLOFs), made more likely by heavier glacial melt. Recent protective rituals respond to fear of invasion and fear of the GLOF.

In the GNH and conservation policies as in the temple rituals, planetary relations seem to occasion another layer of sacralization over previous sediments of sacrality. Over centuries Vajrayana Buddhism in Bhutan has incorporated the various beings and practices of pre-existing landscape relations into a broader sacred geography with nationalist and Buddhist significances. Scholars have sometimes called that process mandalization: incorporating into a geographic mandala local place divinities, thus bringing them and the associated practices into a hierarchical scheme of landscape significance, oriented to an overall narrative of Buddhism taming chthonic forces and superseding archaic practices (Huber 1999). A form of mandalization continues as Bhutan incorporates climate policies and capitalist forces into its sense of sanctuary, taming new suprahuman forces. The process, of course, changes its reception of Buddhism in the process (Branch 2013). Seeing Bhutan allied with science-based conservation and the social psychology of happiness, some now go there to take refuge not in the Buddha exactly, but in the enlightenment of Bhutan. If that seems like tactical sacralization, recruiting global anxieties about climate change and development to make Bhutan a land deserving of regard and patronage, it is part of a long tradition of narrating Bhutan as refuge from exogenous pressures.

Meeting with policy leaders in Thimpu, the capitol city, our faculty from Environmental Science and Law pressed for details: what specific land management policies were being implemented in what ways? Meanwhile faculty from Religious Studies conferred with colleagues from the Royal University of Bhutan who had joined our team on-site: to what extent are Buddhist teachings mobilized to support those policies, through what interpretations? As a team we sought to create an itinerary that would take us into the convergence of those two sets of questions.

Two days switchbacking over mountain passes, negotiating roads cut into the side of steep gorges, brought us to Tharpaling monastery. Perched midway up a mountain dividing the valleys of Chumey and Bumthang, the monastery is associated with the 14th century master Longchen, who systematized five hundred years of previous Buddhist teachings in his work Seven Treasuries. Longchen was abbot of one of the most important monasteries in Tibet but fell afoul of religious politics during Mongol pressure on that land and was forced into exile in Bhutan. Eventually he took refuge in Tharpaling. In preparation for Bhutan our team read a text more influential in regional folk culture, its lines taken up in many stories and songs. Translated into English as Forests of Poetry, Rivers of Composition by the contemporary novelist Ura (2016), the poem describes the valley of Bumthang as a hitherto unknown hidden land (beyul). A term admitting multiple meanings, beyul can indicate a sacred place, a valley difficult to find or reach, a site whose subtle energies can be known only by spiritually adept, a retreat ideal for advance spiritual practice, a vault where Buddhist teachings are preserved as a treasure for future generations, or a sanctuary for those seeking political asylum (Childs 1999; Baker 2006; Allison 2019). Among the polyvalence there seems a basic sense in which the beyul can provide a refuge in times of trouble for those capable of recognizing its reality.

What about the troubles of climate change? As we followed the monastery's caretaking khempo, winding up a steep path from the monastery to a ridge crest where Longchen composed his writing, the law professor pressed the question: does not the sacredness imply that this place is perceived as timeless, untouchable by change? He was captivated by the experience, following a maroon-robed monk up a holy mountain; but he also wondered how this experience related to the policy challenges discussed in the capitol. From the perspective of a holy mountain, he speculated, environmental changes might not even register. 
We walked the final several hundred meters through a thicket of wind-snapped prayer flags, attaining a vista to the snowy high mountains at the border with Tibet and over a river silvering through Bumthang Valley below. From here Longchen would have been able to survey the valley he was extolling while looking back to the passes of Tibet, from which he had been exiled. In the poem, Longchen laments that Mongol invasion had diminished the dharma in Tibet but celebrates his discovery of Bumthang. This valley is the best place to pursue liberation, he wrote, and the mountain the center of the universe.

How strongly could an exile from Tibet regard this place as cosmic center? Atop the mountain, we revisited the poem, the khempo pointing to the particular landscape features it names and the Tibetanist scholars offering alternative translations in answer to intent questions from the rest of us. By following the path of its composition, the medieval text had come alive for the lab, whose questions sought interpretive keys to the ongoing significance of the cosmology hosted here. A Tibetanist pointed us to a passage describing Mt. Tharpaling at the center of a mandala, the plants of the surrounding land paying homage to it, on precisely the pattern of the eight-petaled lotus unfolding around Mt. Meru. That suggests a quite strong sense, he said: that Longchen held this mountain as center of the cosmos. And "Tharpa-ling," in he noted, means the place of liberation (tharpa the Tibetan translation for moksha). The law professor's query seems apt: what could ever change such a strong place?

Yet near the end of the poem, Longchen worries that Mongol invasion will eventually reach Bumthang and he laments the diminishment of dharma that he anticipates will result here as it did in Tibet. Taking refuge in the beyul at the foot of the sacred mountain at the center of the cosmos, in the very ling of liberation, did not offer protection from change. Longchen offers no rite or practice that may protect the valley from invasion and calamity. Rather it seems that Longchen offers a way of interpreting those threats and changes-even those that will one day overtake it.

Re-reading the text on Tharpaling, the team developed a hypothesis to bring together its questions: the experience of the sacred is precisely how this tradition recognizes and interprets change. Longchen seems to have reinterpreted the dislocative trauma of exile from Tibet, where he had witnessed the way stresses of political invasion corrupted its specialness, by relocating that experience in a mandala centered at Tharpaling. That operation has happened anew in the many incarnations of Longchen since: new stresses are incorporated into a mandala, putting them into cosmic place and thereby taming them-just as Himalayan Buddhism has regularly presented itself as taming unruly demons. The point is not simply to protect oneself against those changes, those demons, but to understand them rightly. That is one way that a tradition can mobilize interpretive authority amidst disquieting change.

That seemed to offer a template to understand how, through a mixture of conventional religious channels, national politics, and new media narrative, Bhutan mandalizes the stresses acting upon it, the threats of invasion-military, economic, ideological, and climatic. Bhutan presents itself as a beyul for the world, a divine hidden valley in which lie liberating treasures for those who approach in right mind and right desire. Pilgrims (of a certain means) are welcome, in hopes that they will not only appreciate the specialness of Bhutan, but will also come to see their own places and lifeways as standing in relation to Bhutan, and in need of it—a place set-apart, maybe as a divine land, or as a forested land, or simply an alternative social path through the Anthropocene.

The ecological and religious future of Bhutan may depend on the extent to which the outside world regards itself in the mandala that Bhutan makes of it, as periphery to its sacred mountain, awaiting the teachings of its hidden valleys, which must be protected. By allowing the mandala from Tharpaling some interpretive authority over our extractive ecologies and excessive capitalisms, seen now as the equivalent of Mongol invaders, it transforms us into pilgrims and patrons. Bhutan's strategy to survive the Anthropocene thus would be a version of the strategy it has pursued for the last five hundred years: present itself as a sanctuary, a place of spiritual treasure, deserving of patronage and protection. 


\section{Refuge and Exclusion}

Mandalization seems a benign term. Others see in Bhutan an ethnonationalist Vajrayana fascism that has been sublimating vernacular religious and cultural practices for centuries, recently mobilized to expel those whose religious and cultural practices troubled the idea of a unified Buddhist kingdom. In the early 1990s, around 100,000 people, or about one sixth of the population at the time, were declared non-Bhutanese aliens and were forcibly pushed across the border into India and Nepal, where some still live in refugee camps. Some are not Buddhist, some the wrong kind of Buddhist, some speak Nepali instead of Dzongkha. They are all called "Southerners" as a way of designating that their investment in the high-altitude form of ethnic Buddhism regnant in Bhutan is suspect (Hutt 2003). ${ }^{1}$ The processes by which a place is recognized as a beyul also establishes it as territory for a particular community, under the authority of exclusive institutions (Skog 2016).

Sanctuaries generate strong forces of political expulsion and historical sublimation. As they offer asylum for some, they make refugees of others. As they protect one form of interacting with the landscape they may conceal or derogate the history of others (Howe 2016).

Indigenous peoples were continuously interacting with the high plateau for 9000 years before it became Yellowstone National Park, and the Crow People maintain that the land remains rightfully their territory. Yet until the early 2000s, visitors to the Park were told that there was little Native American history there, for the same reason that contemporary tribes did not wish to visit: because they were frightened of its thermal features. Against that laughable assertion research over the past two decades has shown that a number of different peoples travelled long distances along well-known routes, precisely to interact with the unique thermal and geologic features of Yellowstone (Nabakov and Loendorf 2004; MacDonald 2018).

As template of "America's best idea," Yellowstone exported around the world a way of displacing people and erasing their memories in the name of nature. (Those living there do not really belong to this land because they do not properly understand how special it is.) The settler imagination of wilderness, as a special place without people, has often been a genocidal idea: not only legitimating the violent expulsion of indigenous inhabitants, but erasing from the land the histories of its peoples. When those histories are recovered, they may be presented as primeval, implicitly excluding contemporary efforts of indigenous peoples to maintain or re-establish relations with territory.

The landscape currently governed by Palestine, Jordan, and Israel is, most famously among our sites, perceived as a battleground between competing visions of land revealed as holy and promised, as territory for one or another people. For just that reason there is no avoiding it for this project. Ancient literatures written and compiled from this landscape inscribe storied identity into the land differently, with consequences that include crusades, occupation, expulsion, homeland and displacement, finding refuge and being made a refugee. Over the 20th century, Zionism enlisted the landscape by greening deserts, planting forests, destroying olive groves, razing villages, renaming places, erecting settlements, and-perhaps most consequentially—-redirecting water. Who may find refuge here is shaped in part by which scriptural lexicons of territory gain power to enlist landscapes into their cosmopolitical projects.

All that is well known. The question now to ask: how do emergent planetary stresses interact with those dynamics of refuge and expulsion? Scholarship on histories of violence and exclusion at these sanctuaries is robust, but research is just beginning to investigate how those forces may be reshaped by Anthropocene relations. For example, if climatic warming accelerates flows of refugees while decreasing flows of water through the Jordan River basin, what implications will that have for how the waters of the Jordan are imagined and managed? "Crossing the Jordan" names a motif of finding sanctuary in multiple (sometimes rivalrous) religious and political registers. Will new stresses on biophysical flows of the river have recursive effects on religious flows?

1 The notion to mention this issue is entirely mine and cannot be ascribed to anyone else on the Bhutan research team. 
With the bivalence of refuge and exclusion in mind, it should be clear that those questions do not seek simply to uncover new threats to a special place. Communities may find occasion in new stresses to rework inherited dynamics of refuge and exclusion to create new kinds of sanctuary. Part of the lab's itinerary will be led by those working toward a Jordan River Peace Park, a proposed transboundary political and ecological refuge managed by three states and remembering three streams of religious history. Shared water stress, they think, could lead toward shared affiliations with the river. In that case, climate change as shared relation becomes part of the cultural matrix seeking a different kind of sanctuary-an inclusive, pluralist sacred landscape.

Sanctuaries may also be made to protest or ironize forces of refuge and exclusion. Whenever sanctuary is sought or offered-to humans seeking asylum from violence or refuge from unjust governments, to other animals treated badly by farms or zoos, to other species vulnerable to extinction-it implicitly illuminates some violence. The Sanctuary Movement in the U.S., for example, protests hostile immigration policies by enacting asylum. Offering sanctuary to people facing deportation construes their vulnerability as unjust and the exclusionary policies as illegitimate violence. Especially when sanctuary from deportation is created in religious buildings, offering asylum in a designated sacred place seeks to exclude state power in order to protest state policies of exclusion. Understanding futures of belonging in the North American borderlands therefore needs ways to investigate relations of climate change and human migration in connection with ethnonationalism and border walls. The lab has just begun to formulate questions and itinerary for researching those relations. As so many humans are on the move seeking refuge and asylum of various kinds, what new imaginations of sanctuary are emerging?

\section{Multispecies Sacralization}

Nonhuman creatures are also on the move in an era of climate change and mass extinctions, seeking sanctuary. Our lab wonders: how can we acknowledge and include the ways that nonhuman flows and other species participate in processes of sacralization? Describing the lab's conception of sanctuaries (in Section 2 above) I followed a constructivist line, broadly in line with the legacy of Emile Durkheim, in which sacralization expresses social form. That approach permits us to investigate how sacred places are produced from human imaginations. Yet it also seems incomplete, failing to account for the way certain lands seem to lure human imaginations toward ascribing specialness. They may, in a sense, recruit the sanctuary designation.

High mountains, for example, have long seemed to set their own thresholds, to mark a division of worlds. Cultures have responded to them in various ways: in fear, wonder, veneration, and divinization; through rituals of access, prohibitions of entrance, and making prayer retreats on them; by experiencing the mountain as person, or divinity, or as lair of the demonic, or as arena of the sublime. None of those responses are necessary consequences of the tectonic friction that wrinkled a fold of Earth's crust skyward. Yet neither do they seem arbitrary social projections onto inert space; they are responses.

Imagining a landscape, argues anthropologist Ingold (2011), entails participating in the landscape in some way. It is not an event that happens entirely inside the human brain; it is a relational activity, shaped by the contours and creatures of a place as well as by embodied perception and cultural ideas. Yellowstone has both high mountains and rare geothermal features. Its geological character has for millennia spurred a question in humans: what is the etiquette of relation here? While sanctuaries are not natural kinds, landscapes may enlist human propensities to sacralize. In that sense, the mountains and geysers, American Bison and Grey Wolf, collaborate in the cultural construal of a place as special. They entice sacralizing minds and participate in the social processes by which a place is set apart as sacred.

Our lab therefore asks which nonhumans seem to be stimulating sacralization or taking advantage of affordances created by ascriptions of sacredness. In line with interventions from the field of Multispecies Studies, which asks scholars in humanities and social sciences to work beyond humanist 
premises to understand how worlds are constituted with diverse forms of life, Sanctuary Lab attends to the ways sacred places are made from the interaction of multiple species participating together to realize particular possibilities of a certain land (van Dooren et al. 2016). In supplement to Durkheim's account of society, it is not only humans who do religious work.

The Hula Valley in Northern Israel has become a key stop-over for birds migrating between Africa and Eurasia. A marshy wetland drained by the Jewish National Fund in the midcentury Zionist program of landscape modernization, part of it accidentally reflooded in the late 20th century, and exhausted birds quickly found and claimed it. The National Fund protected part of the flooded areas as a sanctuary, which is now globally famous among birders, many of whom make their own kind of pilgrimage there. You could say that Zionism enlists the birds, but maybe the birds have also enlisted Zionism. They are, for now, collaborators in sacralizing.

The birds follow a flyway that traces the rift valley, from the highland headwaters down the Jordan River over the Dead Sea to the Red Sea, taking advantage of the habitats variously protected by religious designations, by militarized security zones, and by ecological reserves. Our lab's itinerary will follow that flyway, traversing this densely sacralized, bitterly contested landscape along a path made by tectonics, marked by water, reproduced by birds seeking refuge. That line holds religious histories and human politics with geological histories and nonhuman projects, affording the lab a way into the entanglement of particular religious futures with particular fates of nonhuman life, coupled together along uncertain, imperiled flightways.

Refugia are areas where special environmental circumstances have enabled a species to survive after extinction in surrounding areas. (For example, the Yellowstone hot springs are refugia for forms of life that were widespread before the cataclysmic change to an oxygen-rich atmosphere.) Tsing (2017) employs the term more broadly, to refer to conditions that provide haven for biocultural processes and multispecies relations from the plantation simplification and destruction that she takes as hallmark of the Anthropocene. Refugia are critical for livable futures, she writes, for from them may resurge the diversity of multispecies arrangements on which valued human ways of life depend.

Consider sanctuaries as biocultural refugia in that sense. Sacred places often protect some unconventional set of multispecies relations, even when they are not explicit ecological reserves. At least, they are usually set aside from plantation principles of simplification, extraction, and indifferent biological substitution. For that reason, places marked and protected as sacred may have a role to play in resilience and resurgence. Because they offer haven to a multiplicity of biocultural arrangements, they protect multispecies possibilities from extinction. That is one reason for the Sacred Natural Sites initiative of the IUCN: "the sacred" marks havens of biocultural diversity.

In Anthropocene conditions sanctuaries thus may take on new functions of refuge. Think of the Anthropocene not as an enduring planetary condition, writes Donna Haraway, but rather as a boundary, a discontinuity marking the transition between epochs (Haraway 2016, p. 100). Sanctuaries can offer haven both to multispecies relations being extinguished in the Anthropocene and to imaginations being excluded from it. For making ways through the Anthropocene discontinuity perhaps we need sanctuaries to harbor as many possibilities for biocultural resurgence and replenishment as there are sacred stories.

Black-Necked Crane migrates each winter to Bhutan's Phobjika Valley from habitats in Tibet and other places in China. Tradition holds that when they first arrive for the year, they circle (clockwise of course) the temple complex overlooking the valley, before settling in the wide plains. Farmers expect their arrival just after harvest, the cranes and humans seeming to time their provisioning to one another. When it appeared that numbers of Black-Necked Crane were decreasing, the king declared that Phobjika should be managed as habitat for Black-Necked Crane, due to its special relationship with Bhutan. Now the valley plains, rare in this land of narrow gorges and therefore under development pressure for farming and tourism, must maintain winter feeding grounds for Black-Necked Crane.

That action seems to have set in motion cultural processes that elevate Black-Necked Crane's status. While cranes have generally been regarded as admirable creatures in Himalayan Buddhism, regularly 
appearing in story and art, until recently the bird did not enjoy special political protection. Now the strong conservation policies in Phobjika seem to stimulate religious veneration and incorporation into the story of Bhutan as beyul. Every mention of the bird is sure to note that by migrating between Tibet and Bhutan, Black-Necked Crane keeps alive the connection between these sacred lands. In fact, a painting hanging in the Royal Society for the Protection of Nature in Thimpu depicts flying Black-necked Cranes connecting the most important sites of Tibet and Bhutan. As development in China invades habitat of the birds, they find sanctuary in Phobjika-repeating a centuries-old pattern. In the sacralization of Black-Necked Crane, the old/new narrative of Bhutan as beyul is told. At the monastery above Phobjika Valley, Black-Necked Crane has recently been inserted into the murals depicting the masters and incarnations around which the narrative of this land is shaped. Meanwhile, the long-legged creatures, regal in posture, walk the Phobjika fields and pastures in confidence that this is their refuge.

Early one morning I awoke in the dark to go to the valley floor with the music professor. He wanted to record the dawn clamor of the cranes. We set up the microphones atop a layer of fresh snow and then waited in the moon-lit fog that lay thick over the warm-watered valley bottom. Dogs skirted around us, mutually wary, loping with territorial purpose and tracking barks from the farmhouse settlements, their own sociality evident. We waited. Snow-muffled steps of herds beginning to think about moving. The silhouette of cows, shaggy horses, and yak, lugubrious in the cold. We waited. Then, still before a hint of dawn, Oriental Skylark began to call, the dispersal of their high-pitched song testifying to great numbers spread throughout the grasses. We waited. Finally, as mountains to the East began to be outlined by the first flush of light, a crane called. It was from a group far up the valley, near the base of the temple complex. Individuals in a group down-valley, nearer to us, answered. A few family groups of three seemed to switch places, wing-beating in opposite directions. As the day brightened the two groups set to full clamor, their high bugling sound ringing off the mountainsides, dispelling the fog. Little Grebe awoke and began patrolling up and down the river. Ruddy Shelduck set aloft due south, away from the hilltop temple complex, now emerging from the crane-dispelled fog.

By waiting upon Black-Necked Crane we encountered a complex assemblage of biosocial relations finding refuge in crane clamor. In order to protect their habitat, no construction, tillage farming, or water channelization is permitted in the valley center. Within that protection, other bird species also find refuge. So do the mixed herds of free-ranging cattle and the broader ecosocial system of pastoral livelihood from a commons. So do the absorbent soils beneath the marsh grasses that (our environmental scientist taught us to see) take in the monsoon rains like a sponge and release them slowly. So do the quasi-feral dogs, moving across those worlds and policing them for their own ends.

In the land of the sacred Black-Necked Crane, domestic, feral, wild, economic, and religious forms of life negotiate a shared common. Phobjika as refugia offers not only Black-Necked Crane a chance to survive, but a set of landscape relations the possibility to make their way together through the harrowing and replenish the possibilities beyond it.

\section{Arts of Attentiveness}

Why spend such time, money, and carbon to assemble the lab in each place? Following Ingold's point that perception of landscapes arises from some form of participating in them, Lane argues for a phenomenological method, in which the researcher's experience has an important role in understanding sacred places. To an extent, Sanctuary Lab follows the supposition that inquiry is enhanced by the collective experience of participating in the landscape under study. This essay's peculiar style highlights the contributive role of experience. But Lane also shows the liabilities of thinking from experience when he writes: "one's actual embodied experience in encountering a place perceived as sacred is crucial, then, to the sense of magic or awe one finally attributes to it" (Lane 2001, p. 53). That could mislead, as if the researcher needs to feel the magic historically ascribed to the place. Worse, it could invite researchers to treat their own experiences as reliable, even superior, knowledge about the specialness of a place. Especially when the majority of the team shares cultural background and 
material privilege, and when their engagements with a place are short, reflecting from experience, as I have done throughout this essay, runs high risks of perspectival distortion and ethnocentric imposition.

Precisely in order to stimulate critical reflection on the frames and practices through which researchers experience a place, Sanctuary Lab includes arts-based practices of attentiveness as part of its method. It is an important reason why each team includes a faculty member from the arts. In places dense with cultural signification, so trodden by paths of pilgrims and tourists that it is hard to experience anything but their overdetermination, exercises of embodied attentiveness offer a way of participating in the landscape, creating an experience from which to ask anew why the place has enticed sacralizing minds from many worlds for thousands of years. They offer a way to walk at once along and askance from the heaviest paths of sacralizing traditions, allowing researchers to reflect on those cultural pathways while also opening themselves to experience the living landscape that has been enlisted into those pathways. The intentionality of an arts exercise compels critical reflection on the mediation of experience.

Mammoth Hot Springs, a short walk from parks headquarters along a road with stores and cafes, is the background to a million selfies. For just that reason, I did not want to go there. Most people come to Yellowstone not as pilgrims to sacred wilderness, of course, but just to gaze at the wonders. The Park was in fact long marketed as "wonderland," a place for the affluent to come see fabulous curiosities. Yet it was here, on the elaborate wooden walkways built to manage the human traffic, that the music professor chose to set up a listening station: a hydrophone dropped into water bubbling from a thermal vent, channeled with an omnidirectional mic to hear variegated surface flows. Skeptical of the venue, the elaborate equipment, and the entire exercise, I slipped on the headphones out of politeness. And then, in spite of my attitude, I found myself confronted with the live presence of an unfinished volcanic event. The steaming, bubbling sounds moving through my mind were made by temporalities and powers greater than the anthropogenic forcings stressing the forest cover above, certainly greater than the colonial forces that drew the boundaries and erected the walkways. In the midst of over-tourist wonderland, I was caught up in wonder at the presences that have attracted sacralizing minds for millennia.

Leaders in Multispecies Studies have called for researchers to create "arts of attentiveness" as a first step toward scholarship that can carry inquiry beyond observational noticing "into the cultivation of skills for both paying attention to others and meaningfully responding" (van Dooren et al. 2016, p. 17). Their hypothesis is that better, integrated forms of knowing rapidly changing worlds are more likely to arise from immersion within their liveliness. Explaining his own phenomenological approach to sacred sites, Ivakhiv suggests bracketing the conventional notion of landscape as inertly objective and adopting a functionally animist perspective, as a way into inquiry from reciprocal relation with a place (Ivakhiv 2001, p. 14). Animist or not, the mode of inquiry involves a normative decision of how to acknowledge and interact with the relations of a place. Deborah Bird Rose and Thomas van Dooren call for multispecies attentiveness as a matter of research ethics: "we understand ethics as an openness to others in the material reality of their own lives ... with their multitude of interdependencies and precarities, their great range of calls, their care and their abundance along with their suffering and their grief" (Rose and van Dooren 2017, p. 124). By listening to the life of Phobjika, we opened our investigation to the many projects of other species who find refuge in the calls of Black-Necked Crane. More happens in that moment than unusual acquisition of data about a contemporary sacralization process; including arts of attentiveness within research protocols invites lab members to acknowledge our research as a multispecies practice, a form of interaction with nonhuman relations.

Before we left Mammoth, the music professor handed out wind instruments made from stones and some simple percussion items, and invited us to play something back for the thermal springs, as a gesture of acknowledgement and gratitude. Uncomfortably participating in this gesture of reciprocity compelled us to reflect on how academics ordinarily come into a place and the unstated ontological terms by which we propose to interact with it. As a practice of art, it was not quite religious, yet as an offering of respect and relation, it was not entirely secular either. The exercise compelled attention 
to contingent premises of embodied experience in the place-our own, our local experts', those of predecessors and of future generations.

Even while pursuing historical perspective and critical knowledge about these places, we thus also seek affect-oriented pathways for attending to the stresses that are making futures. Arts of attentiveness allow researchers to connect disciplinary forms of inquiry with an often-avoided question of basic relations: whose relations convene here and what kind of claims can they make? Acknowledging the question and the conflicts it represents can create an ontological opening, a consideration of arrangements alternative to those currently or even historically dominant. Sometimes in such practices, the art of inquiry can become itself an offering of sanctuary: in the posture of listening, a way of letting imagination attend to the biocultural pasts and possibilities of the place.

\section{Conclusions}

How are Anthropocene relations bearing on religion, and how are religious processes shaping Anthropocene futures? This essay has shared hypotheses and collaborative research practices that have emerged from Sanctuary Lab in hopes of advancing discussion of methods for investigating that lead question. The six sections of the paper have generated six suggestions: (1) the cultural tensions produced by thresholds of sacred space may be intensified by new pressures on boundaries, which may show up in affective experience; (2) sanctuaries can be treated as laboratories for studying how particular cultural processes are interacting with global flows and planetary stresses; (3) ecosocial futures are forged as communities redeploy inherited ways of interpreting new threats and creating refuge from them; (4) insofar as sanctuaries generate forces of expulsion and political violence, planetary stresses interact with those dynamics as well, in uncertain and indeterminate directions; (5) nonhuman species, flows, lands, and forces participate in sacralization processes; (6) arts-based practices of attentiveness can introduce landscape participation into the mode of inquiry, while also driving critical reflection on mediations of experience.

The two key terms of our lead question faded in importance. Those perilous inventions of analysis, "religion" and "Anthropocene," can distort more than they illuminate about what is happening in particular places, relations, and communities. I have treated them as proxies for two knots of critical debate that, when brought together, may advance understanding of how cultural processes are interacting with global flows and planetary stresses in places designated as sanctuary from sovereign powers and exogenous dangers. I have tried to illustrate how "sanctuary" can organize research with potential to contribute toward transdisciplinary studies of coupled human and environmental change. A central challenge for environmental change research is integrating different scales and tempos of change, finding ways to illuminate the frictions and feedbacks among them. The lab has not yet created a fully transdisciplinary approach, I should be clear. A particular challenge remains how to better incorporate the sciences and develop research that helpfully informs environmental change science (Castree 2014; Palsson et al. 2013).

Finally, Inote that feedback from researchers in Sanctuary Lab as well as from early public audiences suggests that interest in its experiment goes beyond advancing academic capacities of investigation. Participants and the public seem drawn to it as a way to search for resilience, looking to the unusual research practices for a signal of how to dwell amidst the frictions and temporalities of this discontinuity. Research outputs from the lab thus seek to engage publics and scholars in a variety of formats: in addition to conventional scholarly articles, we are creating podcasts, short documentary video, musical composition and performance, and creative nonfiction. We have discovered that-especially when they involve researchers collaborating across borders and disciplines-practices of attending, questioning, and sharing can themselves make a kind of refuge.

Funding: This research received no external funding. Sanctuary Lab was initiated with pilot funding from the University of Virginia.

Acknowledgments: While this essay cannot be taken to reflect the views of my collaborators, it is indebted to everyone in Sanctuary Lab, especially Martien Halvorson-Taylor and Kurtis Schaeffer. Encouragement to 
write from this project began in a Luce Foundation working group on the Anthropocene convened at Duke University by Jedediah Purdy and Norman Wirzba, and was further shaped by a conference on "Vulnerability in the Anthropocene," convened by Matthew Wickman and George Handley at Brigham Young University. I am grateful for the feedback from many colleagues in both settings, and to two anonymous reviewers from this journal.

Conflicts of Interest: Author declares no conflict of interest.

\section{References}

Allison, Elizabeth. 2019. Deity Citadels: Sacred Sites of Biocultural Resistance \& Resilience in Bhutan. Religions 10: 268-85.

Baker, Ian. 2006. The Heart of the World. New York: Penguin.

Branch, Matt. 2013. Climate change projects in the land of gross national happiness: Does religion play a role in environmental policy in Bhutan? In How the World's Religions Are Responding to Climate Change. Edited by Robin Globus Veldman, Andrew Szasz and Randolph Haluza-DeLay. New York: Routledge.

Castree, Noel. 2014. The Anthropocene and the Environmental Humanities: Extending the Conversation. Environmental Humanities 5: 233-60. [CrossRef]

Chakrabarty, Dipesh. 2018. Anthropocene time. History and Theory 57: 5-32. [CrossRef]

Chappel, James. 2020. The Logic of Sanctuary: Towards a New Spatial Metaphor for the Study of Global Religion. Journal of the American Academy of Religion 88: 15-34. [CrossRef]

Childs, Geoff. 1999. Refuge and revitalization: Hidden Himalayan sanctuaries (Sbas-yul) and the preservation of Tibet's Imperial Lineage. Acta Orientalia 60: 126-58.

Deane-Drummond, Celia, Sigurd Bergmann, and Markus Vogt. 2017. Religion in the Anthropocene. Eugene: Cascade.

Farrell, Justin. 2015. The Battle for Yellowstone: Morality and the Sacred Roots of Environmental Conflict. Princeton: Princeton University Press.

Haberman, ed. n.d. Understanding Climate Change through Religious Life-Worlds. Bloomington: Indiana University Press.

Haraway, Donna. 2016. Staying with the Trouble: Making Kin in the Chthulucene. Durham: Duke University Press.

Howe, Nicolas. 2016. Landscapes of the Secular: Law, Religion, and American Sacred Space. Chicago: University of Chicago Press.

Huber, Toni. 1999. The Cult of Pure Crystal Mountain: Popular Pilgrimage and Visionary Landscape in Southeast Tibet. New York: Oxford University Press.

Hutt, Michael. 2003. Unbecoming Citizens: Culture, Nationhood, and the Flight of Refugees from Bhutan. New Delhi: Oxford University Press.

Ingold, Tim. 2011. The Perception of the Environment: Essays on Livelihood, Dwelling, and Skill. New York: Routledge Press.

Ivakhiv, Adrian. 2001. Claiming Sacred Ground: Pilgrims and Politics at Glastonbury and Sedona. Bloomington: Indiana University Press.

Jenkins, Willis. 2017. Feasts of the Anthropocene: Beyond Climate Change as Special Object in the Study of Religion. South Atlantic Quarterly 116: 69-81. [CrossRef]

Jenkins, Willis, Evan Berry, and Luke Beck Kreider. 2018. Religion and Climate Change. Annual Review of Environment and Resources 43: 85-108. [CrossRef]

Lane, Belden. 2001. Landscapes of the Sacred: Geography and Narrative in American Spirituality, 2nd ed. Baltimore: Johns Hopkins University Press.

Latour, Bruno. 2014. Agency at the Time of the Anthropocene. New Literary History 45: 1-18. [CrossRef]

Latour, Bruno. 2017. Facing Gaia: Eight Lectures on the New Climatic Regime. Cambridge: Polity Press.

MacDonald, Douglas. 2018. Before Yellowstone: Native American Archaeology in the National Park. Seattle: University of Washington Press.

Mattingly, Cheryl. 2014. Moral Laboratories: Family Peril and the Struggle for a Good Life. Berkeley: University of California Press.

Nabakov, Peter, and Lawrence Loendorf. 2004. Restoring a Presence: American Indians and Yellowstone National Park. Norman: University of Oklahoma Press. 
Palsson, Gisli, Bronislaw Szerszynski, Sverker Sörlin, John Marks, Bernard Avril, Carole Crumley, Heide Hackmann, Poul Holm, John Ingram, Alan Kirman, and et al. 2013. Reconceptualizing the 'Anthropos' in the Anthropocene: Integrating the social sciences and humanities in global environmental change research. Environmental Science \& Policy 28: 3-13.

Purdy, Jedediah. 2015. After Nature: A Politics for the Anthropocene. Cambridge: Harvard University Press.

Rose, Deborah Bird, and Thomas van Dooren. 2017. Encountering a More-Than-Human World: Ethos and the Arts of Witness. In The Routledge Companion to the Environmental Humanities. Edited by Ursula K. Heise, Jon Christensen and Michelle Niemann. New York: Routledge, pp. 120-28.

Schaefer, Donovan. 2015. Religious Affects: Animality, Evolution, and Power. Durham: Duke University Press.

Sideris, Lisa H. 2017. Consecrating Science: Wonder, Knowledge, and the Natural World. Berkeley: University of California Press.

Skog, Lindsay. 2016. Khumbi yullha and the Beyul: Sacred Space and the Cultural Politics of Religion in Khumbu, Nepal. Annals of the American Association of Geographers 107: 546-54. [CrossRef]

Szerszynski, Bronislaw. 2017a. Gods of the Anthropocene: Geo-spiritual formations in the earth's new epoch. Theory, Culture, Society 34: 253-75. [CrossRef]

Szerszynski, Bronislaw. 2017b. From the Anthropocene Epoch to a New Axial Age. In Religion in the Anthropocene. Edited by Celia Deane-Drummond, Sigurd Bergmann and Markus Vogt. Eugene: Wipf \& Stock, pp. $35-52$.

Tercek, Mike. 2019. Nowcasting and Forecasting Fire Severity in Yellowstone; Washington, DC: National Park Service. Available online: https://www.nps.gov/articles/nowcasting-forecasting-fire-severity-in-yellowstone.htm (accessed on 5 March 2020).

Tsing, Anna. 2017. A Threat to Holocene Resurgence Is a Threat to Livability. In The Anthropology of Sustainability. Edited by Marc Brightman and Jerome Lewis. New York: Palgrave Macmillan.

Ura, Dasho Karma. 2016. Longchen's Forests of Poetry and Rivers of Composition in Bhutan. Thimpu: The Centre for Bhutan Studies and GNH Research.

van Dooren, Thom, Eben Kirksey, and Ursula Münster. 2016. Multispecies Studies: Cultivating Arts of Attentiveness. Environmental Humanities 8: 1-23. [CrossRef]

Veldman, Robin, Andrew Szasz, and Randolph Haluza-Delay, eds. 2014. How the World's Religions are Responding to Climate Change. New York: Routledge.

Verschuuren, Bas, Jeffrey McNeely, Gonzalo Oviedo, and Robert Wild. 2012. Introduction: Sacred Natural Sites, the Foundation of Conservation. In Sacred Natural Sites: Conserving Nature and Culture. Edited by Bas Verschuuren, Jeffrey A. McNeely, Gonzalo Oviedo and Robert Wild. New York: Routledge. 